\title{
Mechanisms and potential molecular markers of early response to combination epigenetic therapy in patients with myeloid malignancies
}

\author{
H.B. LIU ${ }^{1,2}$, D. URBANAVICIUS ${ }^{1}$, P. TAN ${ }^{1}$, A. SPENCER ${ }^{1}$ and A.E. DEAR ${ }^{1-3}$ \\ ${ }^{1}$ Australian Centre for Blood Diseases, ${ }^{2}$ Translational Research Division, Eastern Clinical Research Unit, \\ Monash University, Prahran 3181; ${ }^{3}$ Department of Medicine, Eastern Health Clinical School, \\ Monash University, Melbourne, Victoria, Australia
}

Received May 16, 2014; Accepted June 30, 2014

DOI: $10.3892 /$ ijo.2014.2555

\begin{abstract}
Combination epigenetic treatment (EGT) utilizing DNA methyl transferase inhibitors (DNMTi) and histone deacetylase inhibitors (HDACi) may be more efficacious than single agent treatment in myelodysplastic syndromes (MDS) and acute myeloid leukemia (AML). The molecular mechanisms behind the potential clinical efficacy of combination EGT treatment are incompletely understood and the frequently lengthy EGT regimes required to determine clinical response have generated a significant demand for early molecular markers of treatment response. Our study aimed to identify the effect of combination azacitidine (AZA) and panobinostat (LBH589) on expression levels of a panel of genes implicated in the pathogenesis of high-risk MDS or AML in HL-60 cells. We also characterized gene expression profiles in peripheral blood mononuclear (PBMCs) from patients in a recently reported phase Ib/II clinical trial using the combination of AZA and LBH589 and correlated these findings with clinical response to treatment. In vitro analysis demonstrated increased expression of caspase-3, Nor-1, NUR77, p15 INK4B and p21 ${ }^{\text {WAF1/CIP1 }}$ and decreased expression of Bcl-xL in HL-60 cells treated with combination EGT. Analysis of patient samples prior to treatment demonstrated a significant reduction in NUR77 and $\mathrm{p} 21^{\mathrm{WAF} 1 / \mathrm{CIP} 1}$ expression compared to healthy controls. NUR77 and $\mathrm{p} 21^{\mathrm{WAF} 1 / \mathrm{CIP} 1}$ levels were similar between treatment non-responders and responders at screening. Early post first cycle treatment (day 25) analysis demonstrated a significant increase in expression of both NUR77, and $\mathrm{p} 21^{\mathrm{WAF} 1 / \mathrm{CIP} 1}$. A significant increase in $N U R 77$, and $\mathrm{p} 21^{\mathrm{WAF} 1 / \mathrm{CIP} 1}$ together with
\end{abstract}

Correspondence to: Dr Anthony E. Dear, Department of Medicine, Australian Centre for Blood Diseases, Monash University, Level 6, Burnet Tower, 89 Commercial Road, Prahran 3181, Melbourne, Victoria, Australia

E-mail: anthony.dear@monash.edu

Key words: epigenetic therapy, myelodysplasia, molecular marker, HDACi, DNMTi a trend to increase in $\mathrm{p} 15^{\mathrm{INK} 4 \mathrm{~B}}$ first cycle expression was observed in treatment responders compared to non-responders. In summary, combination AZA and LBH589 epigenetic treatment is associated with in vitro and in vivo modulation of genes implicated in the pathogenesis of MDS/AML. Early expression of $N U R 77$ and $\mathrm{p} 21^{\mathrm{WAF} 1 / \mathrm{CIP} 1}$ correlated with clinical response to combination EGT suggesting investigation for potential use as molecular markers of early treatment response may be warranted.

\section{Introduction}

The potential for enhanced therapeutic responses to combination DNMTi and HDACi EGT is predicated on evidence from basic molecular studies identifying interaction of cellular methylation and acetylation machinery in the transcriptional regulation of gene expression $(1,2)$. Subsequent in vitro and in vivo studies, particularly involving hematological malignancies, have identified enhanced regulation of gene expression and responses to combination EGT lending support to basic molecular studies (3-8).

Clinical studies evaluating the efficacy of combination EGT have, in part, contributed to establishing the molecular mechanisms for the observed therapeutic effects of EGT although have failed to consistently demonstrate changes in early global and gene specific methylation or acetylation status correlate with clinical effect (9-12). Given the duration of EGT either alone e.g., AZA or in combination with HDACi frequently requires several cycles to determine evidence of clinical benefit a significant need exists for identification of molecular markers for determination of early response to (combination) EGT in order to facilitate accurate selection of patients for continued epigenetic treatment, avoidance of unnecessary cost and exposure to side effects in patients unlikely to respond, and to avert delays in provision of more appropriate treatments where possible.

Our previous in vitro studies and recent clinical report investigating the effects of combination AZA and HDACi EGT identifies modulation of expression of genes implicated in the pathogenesis of MDS and AML $(8,13,14)$. We sought to characterize the in vitro expression of genes implicated in 
the pathogenesis of MDS/AML and potentially involved in the transcriptional response to the specific combination of AZA and LBH589 EGT in HL-60 cells. In addition we evaluated the temporal expression of genes identified as being regulated from our in vitro studies in peripheral blood mononuclear cells (PBMCs) from trial patients with high-risk MDS and AML receiving combination AZA and LBH589 EGT and correlated these findings with subsequent clinical responses, predominately observed after a minimum of 3 cycles of therapy (14), with a view to identification of potential early molecular markers of combination EGT treatment response.

\section{Materials and methods}

Cell culture. HL-60 cells were cultured in RPMI-1640 (Gibco BRL) containing $10 \%$ heat inactivated fetal calf serum and kept in a $5 \% \mathrm{CO}_{2}$ incubator at $37^{\circ} \mathrm{C}$. Agents: azacitidine (AZA), the kind gift of Celgene, Australia and panobinostat (LBH589), the kind gift of Novartis, Australia, were added to plates for $48 \mathrm{~h}$. AZA was dissolved in $\mathrm{H}_{2} \mathrm{O}$ with $0.2 \%$ acetic acid and used at a final concentration of $1.0 \mu \mathrm{M}$. LBH589 was dissolved in PBS with $1 \%$ DMSO and used at a final concentration of $20 \mathrm{nM}$.

Growth inhibition assay. HL-60 cells in log phase were plated at a density of $0.2 \times 10^{6}$ in $10 \mathrm{ml}$ of medium. Cells were harvested at 48 h. Cell viability was assessed using $0.4 \%$ trypan blue staining immediately after culture. Black staining cells were considered as non-viable cells, and unstained bright cells as viable. All experiments were repeated 3 times with averages displayed graphically.

Normal healthy control and clinical trial patient samples RNA extraction. TRIzol was used to extract RNA from PBMC fractions from healthy donors $(n=7)$ or day 25 samples from patients in a recently completed phase Ib/II clinical trial (14). The clinical trial consisted of a 5-day schedule of AZA followed by LBH589 in high-risk MDS or AML. AZA $75 \mathrm{mg} / \mathrm{m}^{2}$ was injected subcutaneously on days 1-5. LBH589 was administered orally 3 times a week (Mon/Wed/Fri) starting on day 5 for 7 doses of each 28-day cycle. Between January 2010 and January 2012, 40 evaluable patients were enrolled. There were 30 patients with AML and 10 patients with high-risk MDS, 23 patients (Table I) had data enabling evaluation of molecular marker expression and correlation with treatment response determined either 1,3 or 6 months after treatment commencement. Treatment responses were defined according to International Working Group criteria for AML and MDS (15).

\section{$P C R$}

Semi-quantitative reverse transcription-PCR (RT-PCR). RT-PCR was performed on total TRIzol extracted RNA from HL-60 cells untreated or treated for $48 \mathrm{~h}$ with AZA or LBH589 or a combination of AZA and LBH589. The primers used for p2 $1^{\mathrm{WAF} / \mathrm{CIP} 1}$ were: forward, 5'-ATT AGC AGC GGA ACA AGG AGT CAG CAT-3'; and reverse, 5'-CTG TGA AAG ACA CAG AAC AGT ACA GGG T-3'. The primers used for Bcl-xL were: forward, 5'-TTG GAC AAT GGA CTG GTT GA-3'; and reverse, 5'-GTA GAG TGG ATG GTC AGT G-3'. The primers used for caspase-3 were: forward, 5'-GCA GCA AAC CTC AGG GAA AC-3'; and reverse, 5'-TGT CGGCAT ACT GTT TCA GCA-3'. The human $\beta$-actin gene was used as an internal control. The forward primer for $\beta$-actin was 5'-GAC AGG ATG CAG AAG GAG ATT ACT-3' and the reverse primer was 5'-TGA TCC ACA TCT GCT GGA AGG T-3'.

Real-time PCR. Reaction volumes of $20 \mu \mathrm{l}$ contained SYBR Green 1 buffer and forward and reverse primers for target genes. The primers used for Bcl-xL were: forward, 5'-GGC TGG GAT ACT TTT GTG GA-3'; and reverse, 5'-GTA GAG TGG ATG GTC AGT G-3'. The primers used for caspase-3 were: forward, 5'-CAG TGG AGG CCG ACT TCT TG-3'; and reverse, 5'-TGT CGG CAT ACT GTT TCA GCA-3'. The primers used for p15 ${ }^{\mathrm{INK} 4 \mathrm{~B}}$ were: forward, 5'-AGT CAA CCG TTT CGG GAG GC-3'; and reverse, 5'-ACC ACC AGC GTG TCC AGG AAG-3'. The primers used for $\mathrm{p} 21^{\mathrm{WAF} / \mathrm{CIP} 1}$ were: forward, 5'-TGG ACC TGT CAC TGT CTT GT-3'; and reverse, 5'-TCC TGT GGG CGG ATT AG-3'. The primers used for Nor-1 were: forward, 5'-GTC CTC AGA CTT TCC ATC AGG T-3'; and reverse, 5'-GAT CAG TAA ATC CCG GAA TCC-3'. The primers used for NUR77 were: forward, 5'-GCT GCA GAA TGA CTC CAC C-3'; and reverse, 5'-ACA GCA GCA CTG GGC TTA-3'. The primers used for $\beta$-actin were forward, 5'-GAC AGG ATG CAG AAG GAG ATT ACT-3'; and reverse, 5'-TGA TCC ACA TCT GCT GGA AGG T-3'. Each PCR run also included wells of no template control (NTC). A melting point dissociation curve generated by the instrument was used to confirm that only a single product was present. The fluorescence data were quantitated using the threshold cycle $(\mathrm{Ct})$ value. Data were normalized to $\beta$-actin and presented as the mean-fold change. PCR of each patient sample was completed a minimum of two times to ensure consistency (8).

Statistical methods. The effects of AZA and LBH589 alone and in combination on HL-60 cell growth, p15 ${ }^{\mathrm{INK} 4 \mathrm{~B}}, \mathrm{p} 21^{\mathrm{WAF} 1 / \mathrm{CIP} 1}$, caspase-3, Bcl-xL, NUR77 and Nor-1 mRNA expression were assessed by Student's t-test and analysis of variance (ANOVA). Data were expressed as means \pm SEM and $\mathrm{p}<0.05$ was considered statistically significant.

\section{Results}

AZA and LBH589 alone and in combination inhibits HL-60 cell growth. We examined the effects of AZA and LBH589 alone or in combination on the growth of the human leukemia cell line HL-60. Cells were exposed to AZA $(1.0 \mu \mathrm{M})$ and/or LBH589 (20 nM) for $\leq 48 \mathrm{~h}$. Treatment doses were selected based on inhibition of cell growth concentrations identified in previous in vitro studies $(3,4,7)$. AZA or LBH589 treatment alone significantly inhibited HL-60 cell growth in vitro with LBH589 being the more potent agent. LBH589 in combination with AZA demonstrated a non-significant increase in inhibition of cell growth over AZA or LBH589 treatment alone (Fig. 1).

Effect of AZA and LBH589 on expression of Bcl-xL, caspase-3, Nor-1, NUR77, p15 ${ }^{I N K 4 B}$ and p21 $1^{\text {WAFI/CIPI }}$ mRNA in $H L-60$ cells. As we have previously identified a combination of other hydroxamate HDACi's and AZA as producing 
Table I. Clinical and molecular response correlation.

\begin{tabular}{|c|c|c|c|c|c|}
\hline Patient & Age/sex & Diagnosis & Best response & NUR77 mRNA induction ${ }^{\mathrm{a}}$ & p21 mRNA induction ${ }^{b}$ \\
\hline 1 & $68 \mathrm{M}$ & MDS & Marrow CR & Yes & NA \\
\hline 2 & $70 \mathrm{M}$ & AML & PR & Yes & Yes \\
\hline 3 & $72 \mathrm{~F}$ & MDS & $\mathrm{CR}$ & Yes & No \\
\hline 4 & $61 \mathrm{M}$ & MDS & Resistant & No & NA \\
\hline 6 & $63 \mathrm{~F}$ & MDS & $\mathrm{CR}$ & Yes & NA \\
\hline 7 & $58 \mathrm{M}$ & AML & Resistant & No & No \\
\hline 8 & $75 \mathrm{M}$ & AML & Resistant & No & No \\
\hline 9 & $72 \mathrm{M}$ & AML & $\mathrm{CR}$ & No & Yes \\
\hline 11 & $73 \mathrm{M}$ & AML & Resistant & No & NA \\
\hline 12 & $67 \mathrm{~F}$ & MDS & PR & Yes & NA \\
\hline 13 & $79 \mathrm{M}$ & MDS & SD & Yes & NA \\
\hline 16 & $72 \mathrm{M}$ & MDS & Resistant & No & No \\
\hline 17 & $60 \mathrm{~F}$ & AML & Resistant & No & Yes \\
\hline 18 & $67 \mathrm{~F}$ & MDS & PR & Yes & Yes \\
\hline 19 & $80 \mathrm{M}$ & AML & Resistant & No & Yes \\
\hline 22 & $78 \mathrm{M}$ & AML & $\mathrm{CR}$ & Yes & Yes \\
\hline 23 & $69 \mathrm{M}$ & AML & Resistant & No & No \\
\hline 24 & $72 \mathrm{M}$ & AML & PR & No & Yes \\
\hline 26 & $75 \mathrm{M}$ & MDS & PD & Yes & No \\
\hline 28 & $69 \mathrm{M}$ & AML & PR & No & Yes \\
\hline 31 & $56 \mathrm{M}$ & AML & Resistant & No & No \\
\hline 33 & $62 \mathrm{~F}$ & MDS & Marrow CR & Yes & No \\
\hline 34 & $70 \mathrm{~F}$ & AML & Resistant & Yes & No \\
\hline
\end{tabular}

a2.5-fold or greater NUR77 induction over Screen. ${ }^{\mathrm{b}} 4$-fold or greater $\mathrm{p} 21^{\mathrm{WAF} / \mathrm{CIP} 1}$ induction over Screen. NA, data not available.

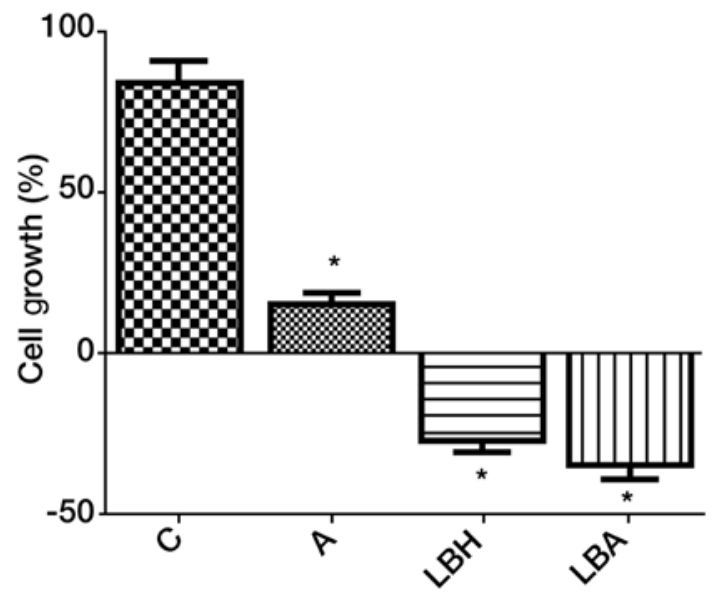

Figure 1. Effects of AZA and/or LBH589 on HL-60 cell growth. HL-60 cells were treated with AZA and/or LBH589 for $48 \mathrm{~h}$. Cell growth $(\%)=$ (the total number of viable cells at $48 \mathrm{~h}$ - the total number of viable cells at the beginning of the experiment / the total number of viable cells at the beginning of the experiments). C, HL-60 cells without treatment; A, 1.0 $\mu \mathrm{M}$ AZA; LBH, $20 \mathrm{nM}$ LBH589; LBA, $20 \mathrm{nM}$ LBH589 + $1.0 \mu$ M AZA. "p $<0.001$ vs $\mathrm{C}, \mathrm{n}=3$.

modulation of several genes implicated in the pathogenesis of MDS including the putative tumor suppressor gene NUR77 $(8,13,16)$ we were interested in determining the effect of the hydroxamate HDACi LBH589 in combination with AZA on gene expression in HL-60 cells. LBH589 or AZA alone increased $\mathrm{p} 21^{\mathrm{WAF} 1 / \mathrm{CIP} 1}$ and caspase-3 expression with LBH589 being the more potent agent (Fig. 2A). The combination of AZA with LBH589 demonstrated a non-significant increase in $\mathrm{p} 21^{\mathrm{WAF} 1 / \mathrm{CIP}}$ expression over single agent treatment (Fig. 2A). LBH589 or AZA alone significantly decreased expression of Bcl-xL expression and the combination of AZA with LBH589 significantly decreased Bcl-xL expression over single agent treatment (Fig. 2A).

Real-time PCR analysis demonstrated AZA, and LBH589 alone significantly increased expression of the novel tumor suppressor genes, $N U R 77$, Nor-1 and p15 ${ }^{\text {INK4B }}$ with LBH589 demonstrating a more potent single agent effect in relation to induction of NUR77 expression (Fig. 2B). The combination of AZA with LBH589 identified a non-significant increase in $\mathrm{p} 15^{\mathrm{INK} 4 \mathrm{~B}}, N U R 77$ and Nor-1 expression over single agent treatment (Fig. 2B).

Effect of AZA and LBH589 on the expression of Bcl-xL, caspase-3, Nor-1, NUR77, p15 INK4B and p21 $1^{\text {WAFI/CIP1 }} \mathrm{mRNA}$ in patient samples. Analysis of gene expression in patient samples prior to treatment (screening) demonstrated a significant reduction in NUR77 and $\mathrm{p} 21^{\mathrm{WAF} 1 / \mathrm{CIP} 1} \mathrm{mRNA}$ expression compared to healthy controls (Fig. 3A). NUR77 and p21 ${ }^{\mathrm{WAF} 1 / \mathrm{CIP} 1}$ 

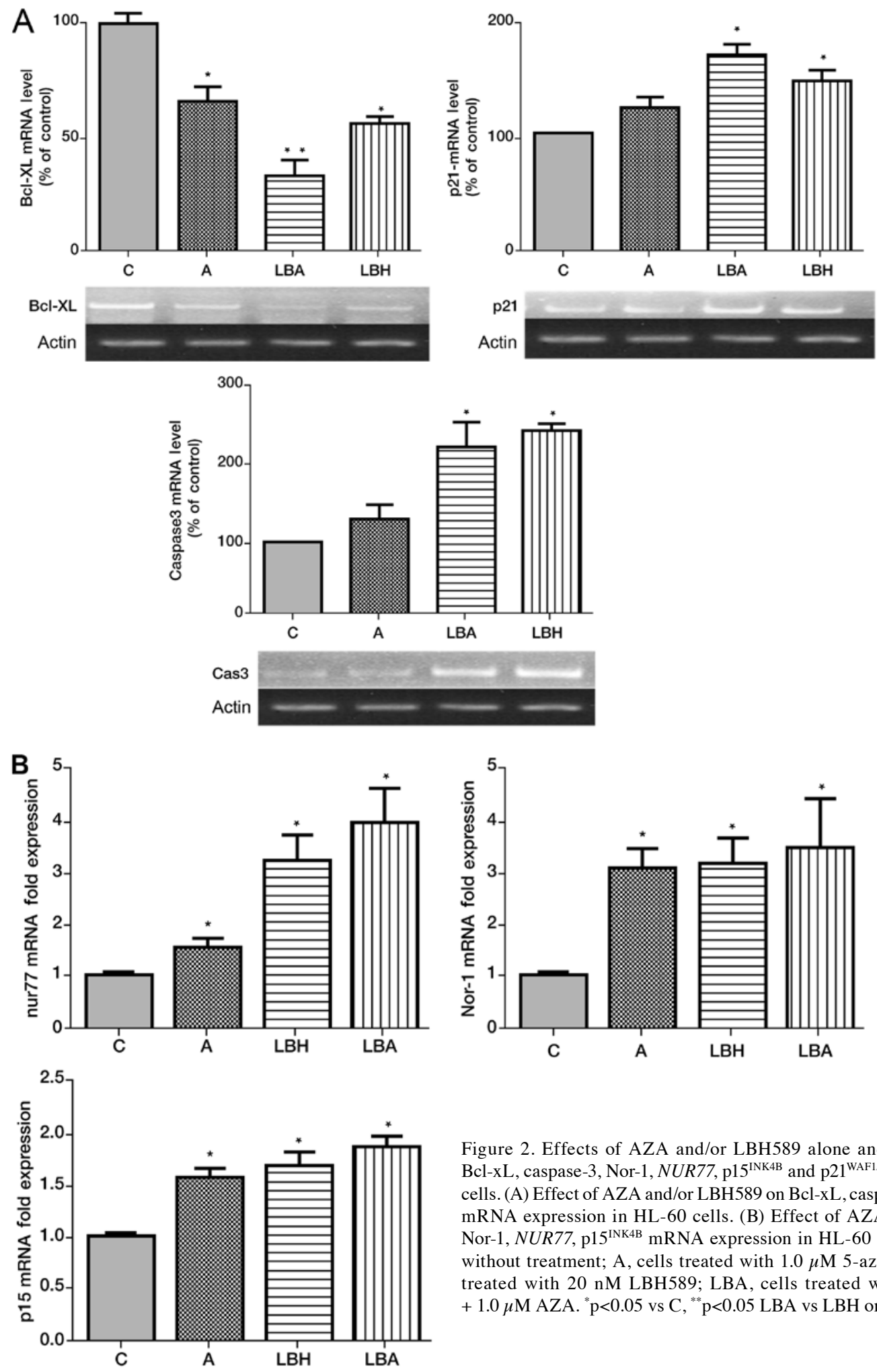

mRNA expression levels were similar between treatment non-responders and responders at screening (Fig. 3B). Post treatment (day 25, first cycle) demonstrated a significant increase in expression of both $N U R 77$, and $\mathrm{p} 21^{\mathrm{WAF} 1 / \mathrm{CIP} 1}$ ranging from 1.5- to 6-fold over screening levels (Fig. 3C). Importantly a significant increase in NUR77, and p21 ${ }^{\mathrm{WAF} 1 / \mathrm{CIP1}}$ (Table I and Fig. 3C) together with a trend to increase in p15 $5^{\text {INK4B }}$ expression was observed in treatment responders compared to non-responders (Fig. 3C).

\section{Discussion}

Novel epigenetic treatments for myelodysplastic syndrome (MDS) including DNA methyl transferase inhibitors (DNMTi) and potentially histone deacetylase inhibitors (HDACi) are able to improve survival $(17,18)$. However, not all patients respond and treatment regimens are often lengthy with responses frequently only observed after several cycles of therapy $(17,18)$. In order to reduce unnecessary treatment exposure, associ- 

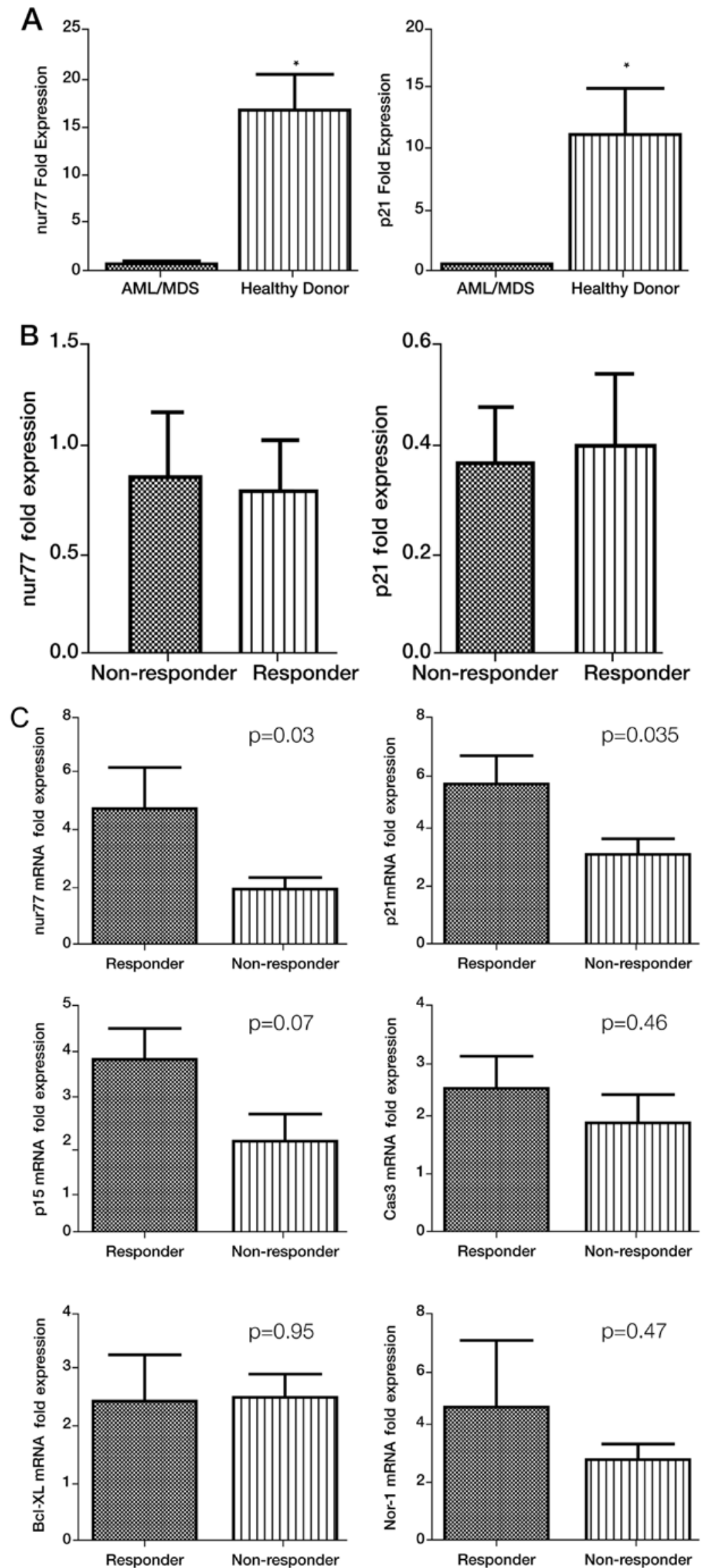

Figure 3. Effects of combination LBH589 and AZA on Bcl-xL, caspase-3, Nor-1, NUR77, p15 $5^{\mathrm{INK} 4 \mathrm{~B}}$ and $\mathrm{p} 21^{\mathrm{WAF} 1 / \mathrm{CIP} 1}$ expression and correlation with clinical response in PBMC's. (A) Pre-treatment patient and healthy control $N U R 77$ and $\mathrm{p} 21^{\mathrm{WAF} / \mathrm{CIP} 1} \mathrm{mRNA}$ expression levels. (B) Pre-treatment $N U R 77$ and $\mathrm{p} 21^{\mathrm{WAF} / \mathrm{CIP} 1}$ mRNA expression levels for responders and non-responders. (C) Correlation of gene expression with clinical response to epigenetic treatment, day $25 \mathrm{mRNA}$ expression levels for NUR77, $\mathrm{p} 21^{\mathrm{WAF} / \mathrm{CIP} 1}, \mathrm{p} 15^{\mathrm{INK} 4 \mathrm{~B}}$, caspase-3, Bcl-xL and NOR-1 correlated with clinical response to treatment determined at 1, 3 and 6 months. $\mathrm{n}=23, \mathrm{p}<0.05$ deemed significant. Responses were defined according to International Working Group criteria for AML and MDS (15). 
ated complications and delays in commencement of other potentially effective therapies a significant demand exists for molecular markers to improve early prediction of response to epigenetic therapy, particularly as baseline and early treatment epigenetic modifications including methylation and acetylation status may not inform on this issue $(9,10,17,18)$.

LBH589 is a novel cinnamic hydroxamic acid analog with established antitumor activity in pre-clinical models (19). LBH589 has demonstrated limited single-agent activity in advanced acute leukemia (20). Interestingly our in vitro observations identified LBH589 as a more potent single agent than AZA with the combination of LBH589 and AZA demonstrating a non-significant increase in potency in inhibition of cell growth over single agent treatment. Single agent treatment demonstrated induction of $\mathrm{p} 15^{\mathrm{INK} 4 \mathrm{~B}}, \mathrm{p} 21^{\mathrm{WAF} 1 / \mathrm{CIP} 1}, N U R 77$, Nor1 and caspase- 3 together with suppression of Bcl-xl expression with LBH589 demonstrating greater potency and a nonsignificant trend to enhanced modulation of gene expression with combination treatment.

Having identified significant in vitro modulation of several genes implicated in the pathogenesis of MDS/AML we were interested to identify temporal expression profiles for these genes in PBMC samples from high-risk MDS/AML patients receiving combination AZA and LBH589 therapy in our recently reported phase $1 \mathrm{~b} / \mathrm{II}$ clinical trial (14). Analysis of NUR77 and $\mathrm{p} 21^{\mathrm{WAF} 1 / \mathrm{CIP} 1}$ expression in patients compared with healthy controls identified significantly reduced expression of both NUR77 and p21 ${ }^{\mathrm{WAF} 1 / \mathrm{CIP} 1}$ compared with healthy controls as has been previously demonstrated $(16,21)$. Screening levels of both NUR77 and p21 ${ }^{\mathrm{WAF} 1 / \mathrm{CIP} 1}$ demonstrated no significant correlation with clinical response to therapy (Fig. 3B) similar to several previous studies undertaking analysis of other epigenetic markers in response to single or combination EGT (18). However determination of NUR77 and $\mathrm{p} 21^{\mathrm{WAF} 1 / \mathrm{CIP} 1}$ expression levels, compared with other genes implicated in the pathogenesis of MDS/AML, from early treatment time-points (day 25), demonstrated a significant correlation with clinical response (Fig. 3C and Table I). Whilst our observation is not unprecedented, for example Link and colleagues demonstrated a statistically significant concordance between response to AZA therapy and induction of p53-inducible-ribonucleotide-reductase (p53R2) (22) these findings were only noted post several cycles of therapy. Identification of $N U R 77$ as a primary inhibitor of leukemogenesis (16), upregulation of NUR77 in primary AML cells and leukemic stems cells in response to epigenetic treatment (23) and early response of NUR77 expression to EGT together with strong correlation with clinical response suggests the identification of a potentially novel molecular marker of early response to combination EGT in the setting of MDS/AML. Unlike other potential indirect molecular markers of EGT treatment response e.g., global or gene specific, methylation/acetylation status the delineation of the critical molecular involvement of NUR77 in the leukemogenesis process, its ubiquitously reduced expression in AML/MDS compared to healthy controls and its early upregulation and correlation with clinical response posits a compelling argument for an early molecular marker of response to combination EGT in MDS/AML. Interestingly, whilst in vitro expression levels of the related orphan nuclear receptor Nor-1 were significantly upregulated by combination EGT and previous in vivo studies have demonstrated downpregulation of Nor-1 in patient leukemic blasts (16) no significant correlation between clinical response and early Nor-1 expression was observed in our study suggesting that NUR77 has a more central role in the early and subsequent clinical response to combination EGT.

Our in vitro and in vivo observations identified significant modulation of expression of apoptosis machinery molecules including Bcl-xL and caspase-3, previously identified as important in mediating the therapeutic effects of EGT (24), although neither demonstrated a significant correlation with clinical response (Figs. 1-3). NUR77 has also been identified to play a critical upstream role in mitochondrial-mediated apoptotic events translocating from nucleus to mitochondria, binding $\mathrm{Bcl}-2$ and releasing cytochrome $c$ with resultant induction of apoptosis $(25,26)$. The critical molecular and upstream role of $N U R 77$ in the leukemogenic process as opposed to the effector functions of Bcl-xL and caspase- 3 may potentially explain why EGT-mediated restitution of NUR77 and not Bcl-xL and caspase-3 expression levels is associated with subsequent clinical response.

Our results also identified a trend toward early upregulation of $\mathrm{p} 15^{\mathrm{INK} 4 \mathrm{~B}}$ and clinical response. The effects of AZA alone and in combination with HDACi on $\mathrm{p} 15^{\mathrm{INK} 4 \mathrm{~B}}$ expression are well documented and have been thought pivotal in the therapeutic activity of this agent in $\operatorname{MDS}(8,13,27-29)$. Indeed early studies showed that promoter methylation of the $\mathrm{p} 15^{\mathrm{INK} 4 \mathrm{~B}}$ gene was associated with disease progression in MDS and that the $\mathrm{p} 15^{\mathrm{INK} 4 \mathrm{~B}}$ promoter was demethylated during treatment with AZA at an early time-point (28). However, baseline and early treatment methylation status has subsequently been demonstrated not to predict response to epigenetic therapy $(9,10)$ and early re-expression of $p 15^{\text {INK4B }}$ is not associated with clinical response $(30,31)$. Together these results suggest whilst $\mathrm{p} 15^{\mathrm{INK} 4 \mathrm{~B}}$ expression may be modulated in response to EGT it is unlikely to serve as a robust molecular marker of early epigenetic treatment response and subsequent clinical response.

In conclusion, our observations identify potential molecular mechanisms associated with combination AZA and LBH589 treatment in in vitro and in vivo settings and posit an argument for prospective clinical investigation of orphan nuclear receptor NUR77 and cyclin-dependent kinase inhibitor $\mathrm{p} 21^{\mathrm{WAF} 1 / \mathrm{CIP} 1}$ as potential molecular markers of early response to combination AZA and HDACi EGT in the setting of MDS and AML.

\section{References}

1. Feinberg AP and Tycko B: The history of cancer epigenetics. Nat Rev Cancer 4: 143-153, 2004.

2. Bolden JE, Peart MJ and Johnstone RW: Anticancer activities of histone deacetylase inhibitors. Nat Rev Drug Discov 5: 769-784, 2006.

3. Cameron EE, Bachman KE, Myohanen S, Herman JG and Baylin SB: Synergy of demethylation and histone deacetylase inhibition in the re-expression of genes silenced in cancer. Nat Genet 21: 103-107, 1999.

4. Gore SD, Baylin S and Sugar E: Combined DNA methyltransferase and histone deacetylase inhibition in the treatment of myeloid neoplasms. Cancer Res 66: 6361-6369, 2006.

5. Griffiths EA and Gore SD: DNA methyltransferase and histone deacetylase inhibitors in the treatment of myelodysplastic syndromes. Semin Hematol 45: 23-30, 2008. 
6. Yang H, Hoshino K, Sanchez-Gonzalez B, Kantarjian H and Garcia-Manero G: Antileukemia activity of the combination of 5-aza-2'-deoxycytidine with valproic acid. Leuk Res 29: 739-748, 2005.

7. Shaker S, Bernstein M, Momparler LF and Momparler RL: Preclinical evaluation of antineoplastic activity of inhibitors of DNA methylation (5-aza-2'-deoxycytidine) and histone deacetylation (trichostatin A, depsipeptide) in combination against myeloid leukemic cells. Leuk Res 27: 437-444, 2003.

8. Liu HB, Mayes PA, Perlmutter P, McKendrick JJ and Dear AE: The anti-leukemic effect and molecular mechanisms of novel hydroxamate and benzamide histone deacetylase inhibitors with 5-aza-cytidine. Int J Oncol 38: 1421-1425, 2011.

9. Shen L, Kantarjian H, Guo Y, Lin E, Shan J, Huang X, Berry D, Ahmed S, Zhu W, Pierce S, Kondo Y, Oki Y, Jelinek J, Saba H, Estey E and Issa JP: DNA methylation predicts survival and response to therapy in patients with myelodysplastic syndromes. J Clin Oncol 28: 605-613, 2010.

10. Fandy TE, Herman JG, Kerns P, Jiemjit A, Sugar EA, Choi SH, Yang AS, Aucott T, Dauses T, Odchimar-Reissig R, Licht J, McConnell MJ, Nasrallah C, Kim MK, Zhang W, Sun Y, Murgo A, Espinoza-Delgado I, Oteiza K, Owoeye I, Silverman LR, Gore SD and Carraway HE: Early epigenetic changes and DNA damage do not predict clinical response in an overlapping schedule of 5 -azacytidine and entinostat in patients with myeloid malignancies. Blood 114: 2764-2773, 2009.

11. Prince HM, Bishton MJ and Harrison SJ: Clinical studies of histone deacetylase inhibitors. Clin Cancer Res 15: 3958-3969, 2009.

12. Lane AA and Chabner BA: Histone deacetylase inhibitors in cancer therapy. J Clin Oncol 27: 5459-5468, 2009.

13. Liu HB, Voso MT, Gumiero D, Duong J, McKendrick JJ and Dear AE: The anti-leukemic effect of a novel histone deacetylase inhibitor MCT-1 and 5-aza-cytidine involves augmentation of Nur77 and inhibition of MMP-9 expression. Int J Oncol 34 573-579, 2009.

14. Tan P, Wei A, Mithraprabhu S, Cummings N, Liu H, Perugini M, Reed K, Avery S, Patil S, Walker P, Mollee P, Grigg A, D'Andrea R, Dear A and Spencer A: Dual epigenetic targeting with panobinostat and azacitidine in acute myeloid leukemia and high-risk myelodysplastic syndrome. Blood Cancer J 4: e170, 2014.

15. Cheson BD, Greenberg PL, Bennett JM, et al: Clinical application and proposal for modification of the International Working Group (IWG) response criteria in myelodysplasia. Blood 108 419-425, 2006.

16. Mullican SE, Zhang S, Konopleva M, Ruvolo V, Andreeff M, Millbrant J and Conneely OM: Abrogation of nuclear receptors $\mathrm{Nr} 4 \mathrm{a} 3$ and Nr4a1 leads to development of acute myeloid leukemia Nat Med 13: 730-735, 2007.

17. Fenaux P, Mufti GJ, Hellstrom-Lindberg E, et al: Efficacy of azacitidine compared with that of conventional care regimens in the treatment of higher-risk myelodysplastic syndromes: a randomised, open-label, phase III study. Lancet Oncol 10: 223-232, 2009

18. Tan PT and Wei AH: The epigenomics revolution in myelodysplasia: a clinico-pathological perspective. Pathology 243 . 536-546, 2011.

19. Matthews GM, Lefebure M, Doyle MA, Shortt J, Ellul J, Chesi M, Banks KM, Vidacs E, Faulkner D, Atadja P, Bergsagel PL and Johnstone RW: Preclinical screening of histone deacetylase inhibitors combined with ABT-737, rhTRAIL/MD5-1 or 5-azacytidine using syngeneic Vk*MYC multiple myeloma. Cell Death Dis 4: e798, 2013.
20. Giles F, Fischer T, Cortes J, Garcia-Manero G, Beck J, Ravandi F, Masson E, Rae P, Laird G, Sharma S, Kantarjian H, Dugan M, Albitar M and Bhalla K: A phase 1 study of intravenous LBH589, a novel cinnamic hydroxamic acid analogue histone deacetylase inhibitor, in patients with refractory hematologic malignancies Clin Cancer Res 12: 4628-4635, 2006.

21. Xiao Y, Wang J, Song H, Zou P, Zhou D and Liu L: CD34 ${ }^{+}$cells from patients with myelodysplastic syndrome present different p21 dependent premature senescence. Leuk Res 37: 333-340, 2013.

22. Link PA, Baer MR, James SR, Jones DA and Karpf AR: p53-inducible ribonucleotide reductase (p53R2/RRM2B) is a DNA hypomethylation-independent decitabine gene target that correlates with clinical response in myelodysplastic syndrome/ acute myelogenous leukemia. Cancer Res 68: 9358-9366, 2008

23. Zhou L, Ruvolo VR, McQueen T, Chen W, Samudio IJ, Conneely O, Konopleva M and Andreeff M: HDAC inhibition by SNDX-275 (Entinostat) restores expression of silenced leukemia-associated transcription factors Nur77 and Norl and of key pro-apoptotic proteins in AML. Leukemia 27: 1358-1368, 2013.

24. Sonnemann J, Hartwig M, Plath A, Saravana Kumar K, Muller C and Beck JF: Histone deacetylase inhibitors require caspase activity to induce apoptosis in lung and prostate carcinoma cells. Cancer Lett 232: 148-160, 2006.

25. Ekert PG and Vaux DL: The mitochondrial death squad: hardened killers or innocent bystanders? Curr Opin Cell Biol 17 626-630, 2005.

26. Lin B, Kolluri SK, Lin F, Liu W, Han YH, Cao X, Dawson MI, Reed JC and Zhang XK: Conversion of Bcl-2 from protector to killer by interaction with nuclear orphan receptor Nur77/TR3. Cell 116: 527-540, 2004.

27. Uchida T, Kinoshita T, Nagai H, Nakahara Y, Saito H, Hotta T and Murate T: Hypermethylation of the $\mathrm{p} 15^{\mathrm{INK} 4 \mathrm{~B}}$ gene in myelodysplastic syndromes. Blood 90: 1403-1409, 1997.

28. Daskalakis M, Nguyen TT, Nguyen C, Guldberg P, Kohler G, Wijermans P, Jones PA and Lübbert M: Demethylation of a hypermethylated P15/INK4B gene in patients with myelodysplastic syndrome by 5-Aza-2'-deoxycytidine (decitabine) treatment.. Blood 100: 2957-2964, 2002.

29. Hitomi T, Matsuzaki Y, Yokota T, Takaoka Y and Sakai T: p15(INK4B) in HDAC inhibitor-induced growth arrest. FEBS Lett 554: 347-350, 2003.

30. Soriano AO, Yang H, Faderl S, Estrov Z, Giles F, Ravandi F, Cortes J, Wierda WG, Ouzounian S, Quezada A, Pierce S, Estey EH, Issa JP, Kantarjian HM and Garcia-Manero G: Safety and clinical activity of the combination of 5-azacytidine, valproic acid, and all-trans retinoic acid in acute myeloid leukemia and myelodysplastic syndrome. Blood 110: 2302-2308, 2007.

31. Garcia-Manero G, Kantarjian HM, Sanchez-Gonzalez B, Yang H, Rosner G, Verstovsek S, Rytting M, Wierda WG, Ravandi F, Koller C, Xiao L, Faderl S, Estrov Z, Cortes J, O'brien S, Estey E, Bueso-Ramos C, Fiorentino J, Jabbour E and Issa JP: Phase 1/2 study of the combination of 5-aza-2'-deoxycytidine with valproic acid in patients with leukemia. Blood 108: 3271-3279, 2006 